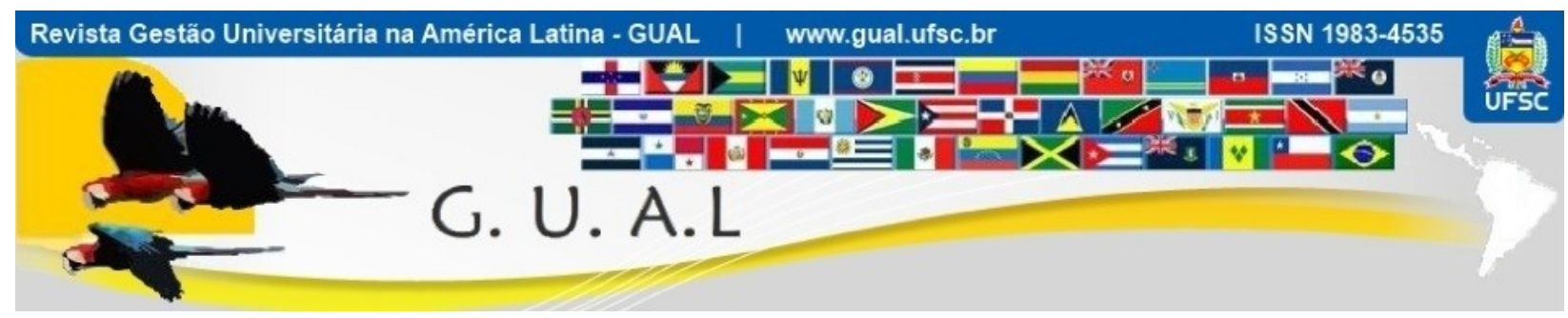

DOI: http://dx.doi.org/10.5007/1983-4535.2014v9n4p255

\title{
GESTÃO DA DOCÊNCIA UNIVERSITÁRIA: O STRESS NA VIDA DOS PROFESSORES INICIANTES
}

\section{MANAGEMENT OF UNIVERSITY TEACHING: THE STRESS IN THE LIFE OF BEGINNING PROFESSORS}

Gionara Tauchen, Doutora

Universidade Federal do Rio Grande - FURG giotauchen@gmail.com

Fernanda Fátima Cofferri, Mestre Universidade Federal do Rio Grande - FURG fernandacofferri@hotmail.com

Eliana Ortiz Castilla, Mestre Universidad del Rosario eliana_ortiz05@yahoo.es

Bruna Telmo Alvarenga, Doutoranda Universidade Federal do Rio Grande - FURG brunatelmoalvarenga@gmail.com

Daniele Simões Borges, Doutoranda Universidade Federal do Rio Grande - FURG daniele.uab@gmail.com

Camila Ferreira Pinto das Neves, Doutora Universidade Federal do Rio Grande - FURG camilapinto.eco@gmail.com

Recebido em 04/dezembro/2015

Aprovado em 14/outubro/2016

Sistema de Avaliação: Double Blind Review

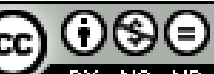

Esta obra está sob uma Licença Creative Commons Atribuição-Uso. 


\title{
RESUMO
}

A docência universitária é uma atividade profissional complexa e vem sendo reconfigurada pelas mudanças políticas, educacionais e econômicas que, muitas vezes, produzem situações de stress, excesso de trabalho e insatisfação profissional. Por isso, o presente artigo tem por objetivo compreender as percepções dos docentes universitários iniciantes sobre as situações de stress envolvidas no desempenho das suas atividades e funções. Foram entrevistados oito professores em exercício em uma universidade pública do estado do Rio Grande do Sul. A partir da produção e análise dos dados, mediante pesquisa qualitativa do tipo narrativa, as considerações dos entrevistados evidenciam que, muitas vezes, se sentem despreparados em situações de ensino, pressionados pelas demandas de produtividade científica, desconfortos ao lidar com situações administrativas e sobrecarga de atividades, principalmente no ensino e na gestão. Para lidar com situações de stress, os docentes desenvolvem processos de adaptação individual e coletiva e aprendem na prática como contornar as situações adversas que vivenciam, no cotidiano. Acreditamos que os docentes iniciantes têm anseios de promover uma educação de qualidade, apesar das adversidades e incertezas, pois sentem prazer na profissão e consideram ser professor universitário uma conquista e realização.

Palavras-chave: Docente iniciante. Stress. Universidade. Ensino.

\begin{abstract}
Teaching in university is a complex professional activity, that has been reconfigured by political, educational and economic changes that often produce situations of stress, overwork and professional dissatisfaction. Therefore, this article aims to understand the perceptions of beginning university professors about the stress situations involved in the performance of their activities and functions. Eight current professors from a public university in the state of Rio Grande do Sul were interviewed. From the production and analysis of the data, through qualitative research of the narrative type, the considerations of the interviewees show that they often feel unprepared in situations of Teaching, pressured by demands of scientific productivity, discomforts in dealing with administrative situations and overload of activities, especially in teaching and administrative tasks. To deal with stress situations, professors develop individual and collective adaptation processes and learn by practice how to get around the adverse situations they experience in everyday life. We believe that beginning professors are eager to promote quality education, despite adversity and uncertainty, because they take pleasure in the profession and consider being a university professor a conquest and achievement.
\end{abstract}

Key words: Beginning professor. Stress. University. Teaching. 


\section{CONSIDERAÇÕES INICIAIS}

A docência iniciante, principalmente na Educação Superior, vem sendo objeto de muitos estudos (CUNHA, 2013, 2014; NONO, 2005; PAPI e MARTINS, 2010; ZANCHET et al. 2012) os quais, segundo, Cunha e Zanchet (2010), têm abordado experiências de acompanhamento e de formação, a construção dos saberes profissionais, as políticas educacionais e o trabalho docente, entre outros, evidenciando a atenção à problemática da docência iniciante pois, no Brasil, “[...] a política de formação para o ensino superior é realizada de forma indireta" (MOROSINI, 2000, p. 19), pois o Art. 66 da Lei n. 9.394/96 expressa que "a preparação para o exercício do magistério superior far-se-á em nível de pósgraduação [...]”. Para Morosini (2000, p.12), “a principal característica dessa legislação sobre quem é o professor universitário, no âmbito de sua formação didática, é o silêncio [...] partese do princípio de que sua competência advém do domínio da área de conhecimento, na qual atua", não estabelecendo orientações sobre a formação didática e pedagógica para a docência.

Supõe-se que a capacitação profissional seja vocacionada ou construída por meio da experiência. No entanto, cabe-nos questionar as condições de organização e de ressignificação da experiência, pois as mudanças sociais e as reformas educacionais produziram novos fenômenos como a massificação da educação, a diversificação de modelos institucionais e de oferta de formação profissional, a ampliação das funções da universidade e a complexificação das suas relações com a sociedade e a economia, principalmente nos países em desenvolvimento.

Na última década, evidenciam-se ações do governo federal, visando ampliar o acesso e a permanência dos estudantes na Educação Superior. O Programa de Apoio a Planos de Reestruturação e Expansão das Universidades Federais - Reuni, instituído pelo Decreto ${ }^{\circ}$ 6.096, de 24 de abril de 2007, integrado ao Plano de Desenvolvimento da Educação (PDE), por exemplo, é um dos Programas que reforçou o papel das universidades para o desenvolvimento social e econômico do país. O documento do MEC (2009) informa que o Reuni tinha por finalidades garantir às universidades subsídios necessários para a ampliação do acesso e da permanência na Educação Superior; propiciar a qualidade por meio de inovações acadêmicas; proporcionar a articulação entre os diferentes níveis de ensino, integrando a graduação, a pós-graduação, a Educação Básica e a educação profissional e tecnológica; e aperfeiçoar o aproveitamento dos recursos humanos e da infraestrutura das instituições federais de Educação Superior. 
A proposta de expansão, com a reestruturação das instituições, visando a mudança do panorama da Educação Superior no Brasil, impactou, entre outros aspectos, na contratação de novos servidores, pois esta "configura-se como uma das principais demandas do Reuni, para o cumprimento das metas" MEC (2009, p. 8) e, também, como um dos motivadores da elaboração desta pesquisa, pois, a expansão do quadro docente, nas condições em que vêm ocorrendo, aponta para um cenário profissional e institucional desafiador. Nono (2005, p. 42) explica que as pesquisas sobre os professores iniciantes ou principiantes "têm procurado caracterizar esse período de contínuo processo de desenvolvimento profissional docente [...]”, buscando identificar problemas e preocupações dos docentes iniciantes, as transformações no âmbito pessoal, as mudanças da condição de estudante para professor, entre outras, destacando que as mudanças no papel social dos professores, o aumento das responsabilidades e das exigências sociais e educacionais potencializam situações de stress para muitos docentes.

Assim, o presente estudo tem por objetivo compreender as percepções dos docentes universitários iniciantes sobre as situações de stress envolvidas no desempenho das suas atividades e funções.

\section{ABORDAGEM METODOLÓGICA}

Para compreender as especificidades da docência iniciante na universidade, utilizamos a pesquisa qualitativa, do tipo narrativa, fundamentada em Gibbs (2009). A pesquisa qualitativa intenciona o acesso às experiências e interações em seu contexto, de modo que sejam preservadas suas particularidades, sendo fundamental o processo de escrita, desde as notas de campo e transcrições, até a interpretação dos resultados. Schütze (2011, p. 213) afirma que "a entrevista narrativa autobiográfica produz dados textuais que reproduzem de forma completa o entrelaçamento dos acontecimentos e a sedimentação da experiência da história de vida do portador da biografia [...]”.

Nesta perspectiva, para proceder à produção dos dados relativos aos docentes iniciantes, solicitamos à Pró-reitoria de Gestão de Pessoas (PROGEP) a listagem com os cadastros de todos os docentes doutores, ingressantes no quadro efetivo da universidade, entre o período de 2012 a 2014. Para a delimitação dos sujeitos do estudo, analisamos o currículo lattes dos docentes, excluindo da amostra aqueles que possuíam experiências de docência na Educação Superior anterior ao seu ingresso na instituição. Com este movimento, identificamos 47 docentes iniciantes em exercício. 
Devido às possibilidades de acesso e ao grande número de sujeitos, optamos por desenvolver a pesquisa somente com os 29 docentes atuantes no campus sede, localizado no município de Rio Grande, RS. Assim, através dos endereços de email disponibilizados pela instituição, contatamos os docentes iniciantes, convidando-os a participar da pesquisa. Obtivemos retorno de onze docentes interessados em participar do estudo. Porém, devido às agendas dos docentes e a incompatibilidade de horários para realizar as entrevistas, o corpus de análise foi constituído por oito docentes atuantes em sete unidades educacionais ${ }^{\mathrm{i}}$. Essa seleção dos sujeitos da pesquisa obedeceu aos critérios de estar atuando há menos de 3 anos ${ }^{\mathrm{ii}}$ na universidade e não ter exercido a docência, neste nível de ensino, em outro momento de atuação profissional.

A produção das narrativas foi orientada pelas seguintes questões: 1) Como é a sua rotina de trabalho e as atividades que realiza na instituição? 2) Sua atuação na universidade inclui atividades de pesquisa, ensino, extensão e gestão? 3) Você já vivenciou situações de mal-estar ou esgotamento decorrente das atividades no trabalho? Explique. 4) No seu entender, que fatores podem causar o mal-estar docente? Estas situações são enfrentadas? De que maneira? 5) Como você avalia os reflexos do mal-estar no trabalho e nas relações com a universidade e colegas? 6) Qual é o seu sentimento por ser professor na Educação Superior nos dias atuais?

As narrativas foram analisadas conforme proposto por Gibbs (2009): a) realização de leitura para familiarização com os conteúdos; b) escrita de um breve resumo sobre as compreensões principais de cada narrativa; c) anotações e codificação, ao longo do texto, destacando as ideias relacionadas ao tema da pesquisa; d) agrupamento das ideias em eixos temáticos acompanhados por um memorando. Durante a discussão dos resultados, apresentaremos alguns recortes das narrativas, utilizando a codificação referente ao número da narrativa.

Destacamos que os momentos dedicados às entrevistas foram significativos para os entrevistados e para a pesquisadora, pois oportunizaram a compreensão multidimensional e, ao mesmo tempo, particular, das experiências vivenciadas pelos sujeitos, embasada nas expressões e sentimentos demonstrados no espaço-tempo em que foram realizadas as entrevistas.

\section{DOCÊNCIA, ADAPTAÇÃO E STRESS}


A profissão docente, conforme afirma Montero (2005), envolve uma fina trama que "une os aspectos pessoais e profissionais [...] de maneira a evitarmos uma explicação unilateral de uma sobre o outro" (p. 128). Por isso, buscando entender os novos tempos, sujeitos e espaços, questionamos: O que pensam de si mesmos os professores que atuam na Educação Superior? Como o espaço de atuação influencia seu processo de formação? Que atribuições e atividades lhes são exigidas? Como se sentem no desempenho de suas funções? Estas e outras questões suscitam compreensões multidimensionais sobre o exercício docente, pois, conforme expressa Soares et al. (2014, p. 173), "a docência, antes situada no porto seguro de uma universidade voltada para a elite e de hegemonia da ciência moderna positivista, encontra-se, nas ultimas décadas, em águas turbulentas [...]”.

Diversos pesquisadores (MOROSINI, 2000; ZABALZA, 2004; ISAIA e BOLZAN, 2004; CUNHA, 2009; VEIGA, 2014) têm produzido estudos reiterando quão complexa e multifacetada é a docência. De acordo com Pimenta e Anastasiou (2005, p. 142) esta "relação profissional do professor com as instituições de ensino superior inicia-se pelo papel de docente”. Inicia-se com as atividades de ensino, pois, gradativamente, são inseridas múltiplas atividades na rotina do professor, em especial, as funções administrativas. Como consequência, exercer a docência como atividade profissional, segundo Tauchen e Fávero (2014, p. 31), “tornou-se mais complexa com as transformações culturais e com o surgimento de novas condições e exigências de trabalho: massificação da escolarização, novas tecnologias, programas institucionais, entre outros”. Por isso, a profissionalização dos professores “[...] na dupla dimensão de desenvolvimento do estatuto social (profissionalismo) e do saber e competência como valores educativos (profissionalidade)" (MONTERO, 2005, p. 91) precisam ser incluídos como aspirações prioritárias das políticas, dos sistemas e das instituições de ensino, visando à qualidade dos processos educativos.

Para Zabalza (2004, 109), “o exercício da docência, o ato de ensinar, deveria ser o mais importante, porque nele se concentra a tarefa formativa da universidade [...]". No entanto, o que presenciamos, muitas vezes, são aulas desmotivadoras e professores desinteressados pelas atividades de ensino, pois estão focados nas pesquisas e nas produções científicas. Soares et al. (2014, p. 174) explica que

A pós-graduação stricto sensu está voltada apenas para a formação do pesquisador e não contempla adequadamente a formação para a docência universitária. Ademais, o acesso e a progressão na carreira são baseados na produção científica que exige grande investimento de tempo e energia física e mental, que naturalmente restringe de forma significativa as condições desse professor, de garantir a atenção necessária à docência, sobretudo na graduação, e ao seu desenvolvimento profissional docente. 
De acordo com Zabalza (2004), referimos-nos à docência, como o trabalho dos professores voltado para o ensino, mas temos a consciência de que exercem outras atividades como pesquisa, extensão e administração. Atualmente, outras demandas agregam-se a estas, as quais ampliam e tornam cada vez mais complexa a ação docente: busca de financiamento, negociação de projetos, representação social da universidade, criação cursos e programas, criação e manutenção de redes de relacionamento com outras instituições em âmbito nacional e internacional, entre outros.

Neste cenário, é inevitável e desafiadora a adaptação docente nos contextos em que atuam, desenvolvendo competências profissionais para o ensino, a pesquisa, a extensão e a gestão, mantendo estados de equilíbrio pessoal e controle dos fatores do stress e esgotamento profissional. Conforme afirmação de Isaia (2000, p. 32) "o professor e a pessoa do professor não podem estar dissociados sob pena de fragmentar-se a compreensão que dele se possa ter [...]". Por isso, entendemos que a fase inicial de inserção na carreira docente é um período turbulento, porém, fundamental para o "dar-se conta" profissional do professor, já que é no princípio da sua atuação que o professor passa a configurar sua identidade e a sua carreira. Conforme Tardif (2002) essa é uma fase, de fato, importante na história profissional do professor, que determina inclusive o seu futuro e a sua relação com o trabalho com os colegas e as situações que passa a vivenciar na sua prática docente.

Nesta perspectiva, Huberman (2000), ao discorrer sobre o ciclo de vida profissional dos professores, com base no desenvolvimento da carreira, propõe algumas fases para sua compreensão: entrada na carreira de sobrevivência e/ou descoberta; fase de estabilização; fase de experimentação/diversificação; fase de serenidade e distanciamento afetivo; fase de resistência e lamentações; e a última, fase de desinvestimento na carreira. Neste trabalho, abordaremos apenas a primeira fase, visto que, a pesquisa teve como sujeitos os professores iniciantes.

O estágio de "sobrevivência" ou o choque de realidade é percebido como o conflito inicial com a complexidade da atividade profissional, a fragmentação do trabalho, a preocupação consigo mesmo e os conflitos com estudantes e colegas, entre outros aspectos. Por outro lado, o aspecto da "descoberta", remete o entusiasmo e a motivação inicial, o enaltecimento por ter utilidade e responsabilidade em uma instituição. Esses dois aspectos podem ou não ser vivenciados em paralelo, embora, constata-se que a descoberta dá suporte à sobrevivência para que os professores sigam no trabalho docente (HUBERMAN, 2000). 
As pesquisas de Scremin e Isaia (2011, p. 398), reiteram que a atuação docente na universidade não se dá apenas em atividades de ensino:

[...] as funções docentes abarcam toda a tarefa educativa, ou seja, relaciona-se direta e principalmente com o processo de ensino-aprendizagem. Trazendo parte desta definição para o contexto da universidade foi possível confirmar a existência de professores exercendo mais de uma função docente.

As tarefas educativas incluem desde os processos de organização do ensino - seleção de conteúdos, planejamento, acompanhamento e avaliação - até sua vinculação com o projeto pedagógico de curso, o projeto pedagógico institucional e, de forma mais ampla, com as finalidades da Educação Superior. Por isso, em virtude da multidimensionalidade da tarefa educativa, alguns docentes reagem negativamente ao momento inicial da docência e, aos poucos, vão elaborando processos de adaptação.

Tais processos são tramados a partir de movimentos oscilatórios, cujo dinamismo revela avanços e retrocessos, rupturas e resistências na produção de saberes e fazeres docentes. Desse modo, o processo constitutivo de ser professor parte de uma ambiência em que a possibilidade de resiliência docente permite construir algo novo a partir da trajetória pessoal e profissional de cada professor em particular e do grupo como um todo, pautado na autonomia docente (ISAIA e BOLSAN, 2011, p. 188).

Iniciar e permanecer na profissão torna-se desafiador perante as múltiplas exigências que perpassam a prática docente. Modos distintos de conduzir a vida pessoal e profissional são fundamentais, bem como afirmam Limongi-França e Rodrigues (2014, p. 31) "a todo instante estamos fazendo movimentos de adaptação, ou seja, tentativa de nos ajustarmos às mais diferentes exigências, seja do ambiente externo, seja do mundo interno [...]". A adaptação é necessária, pois as situações de stress (positivas ou negativas), vivenciadas na fase da docência iniciante, demonstram a inevitabilidade de adaptações profissionais e pessoais. O stress pode ser compreendido como um estado de tensão, motivador de um desequilíbrio da "sintonia do corpo" (LIPP, 2000). Geralmente são atribuídos apenas aspectos negativos ao stress, ou seja, que o organismo responde negativamente ao estressor, desencadeando um processo adaptativo inadequado, conhecido como distress. Porém, as pessoas podem reagir às situações estressoras de maneira positiva e em benefício próprio e coletivo, entendendo o stress como um processo positivo, denominado de eustress (LIMONGI-FRANÇA e RODRIGUES, 2014).

Segundo Jesus (2002a) a profissão docente é uma das mais estressantes e por isso, é fundamental desenvolver maneiras de lidar com as situações de stress e valorizar os pontos de 
vista otimistas, os bons exemplos e as experiências saudáveis vivenciadas na docência. Para os docentes que têm assumido diversos papeis profissionais, é imprescindível lidar positivamente com os diversos fatores estressores, internos ou externos, buscando manter equilíbrio e a qualidade de vida pessoal e profissional.

\section{DOCENTE INICIANTE: PERCEPÇÕES EM RELEVO}

Há uma multiplicidade de aspectos que integram a docência iniciante e que, consequentemente, pode ser causadores do stress. De acordo com Masetto e Gaeta (2013), essa atividade implica interação de conhecimento, atividades profissionais, estruturas físicas e recursos pedagógicos, envolvendo estudantes, colegas de trabalho e o governo por meio das políticas públicas. É no diálogo com todos esses atores e com as possibilidades de formação que os docentes iniciantes têm se constituído. Nesta perspectiva, a figura abaixo expressa a síntese dos discursos manifestados por meio das entrevistas narrativas realizadas com os docentes iniciantes.

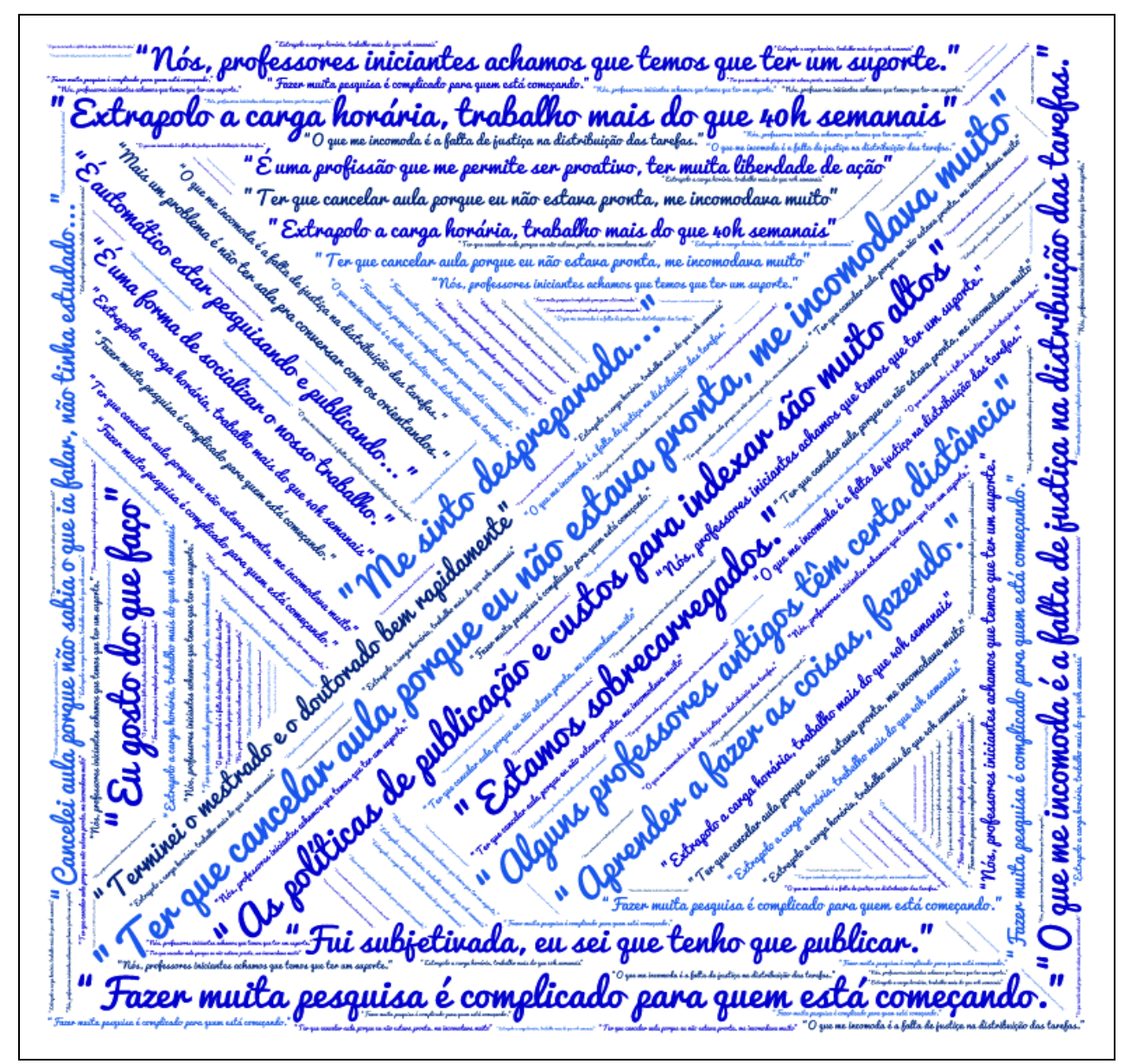

Figura 1 Percepções dos docentes iniciantes.

Fonte: As autoras. 
Por meio do estudo realizado, constatamos que o ingresso na carreira docente foi subsequente à conclusão do doutorado, conforme expressam os participantes da pesquisa: “[...] me sinto lisonjeado por ter conseguido chegar aqui. Foi tudo muito rápido, logo depois que acabei o doutorado aqui, passei de aluno para professor" (D. 2). "Terminei o mestrado e o doutorado bem rapidamente, isso me causa bastante satisfação, conquistar uma vaga na universidade pública e por ser a universidade que eu estudei, isso me dá orgulho [...], mas, tem a parte da cobrança que incomoda um pouquinho" (D. 7).

De acordo com as narrativas, percebemos que a constatação de Huberman (2000) se confirma, com relação à sobrevivência e a descoberta, presentes nesta fase. Apesar das cobranças, das múltiplas atividades e responsabilidades, o exercício da docência universitária consiste em uma realização pessoal muito grande, ou seja, a conquista do seu espaço, o sentimento de se "sentir útil" e a rápida passagem de estudante para professor, constituem a motivação dos docentes para o desempenho das suas atividades. Assim, conforme afirma Nono (2005), o elemento de descoberta tem a ver com o entusiasmo do iniciante, com o orgulho de ser integrante de um corpo profissional.

Os docentes entrevistados também consideram que a atuação na Educação Superior é permeada por muita flexibilidade e liberdade, conforme expressamos no seguinte excerto: "É uma posição na sociedade que me permite ser proativo, ter muita liberdade de ação e me permite ter um papel chave. É isso que eu gosto" (D. 2). Catani (2008, p. 13) corrobora com esse entendimento expressando que "a universidade ainda é esse espaço de liberdade, você ainda tem condições, de alguma forma, de mergulhar em alguns temas, pode discuti-los, aprofundá-los [...]".

Por outro lado, coexiste a solidão profissional:

Me sinto despreparada, porque tenho turma com 80 alunos e na hora da aula soube que havia um aluno surdo na minha turma. Tem a questão dos indígenas e dos quilombolas, essa situação nos pede uma postura para entender que eles [estudantes] têm dificuldades. Fui descobrindo no decorrer do processo como fazer, sem nenhum tipo de instrução. Talvez se eu tivesse recebido uma orientação, pudesse ter conduzido as coisas de um modo diferente. (D. 4)

O período de passagem da vida acadêmica de estudante para a docência foi rápido e, talvez, o despreparo do docente iniciante para lidar com algumas situações se reflita em estados de ansiedade, angústia e desmotivação. A inclusão de estudantes com deficiência, indígenas e quilombolas e a compreensão das dificuldades de aprendizagem e de organização 
dos estudantes, constituem-se situações desafiadoras. Além disso, os entrevistados expressam a necessidade de maior acompanhamento, de orientação e de comunicação institucional.

Cunha et al. (2015, p. 74-75), elucida que

Parece ser um período em que os docentes universitários estão buscando o seu estilo profissional, onde estabelecem os valores que vão se constituindo numa marcante cultura. Entretanto as representações e as ideologias profissionais sugerem o individualismo e os joga numa condição de ambigüidade. Por um lado são cada vez mais responsabilizados pelo sucesso da aprendizagem de seus alunos, bem como pelos produtos de sua condição investigativa. Por outro, a preparação que tiveram não responde às exigências da docência e não foram para ela preparados.

Esta "responsabilidade pelo sucesso dos alunos" se manifesta de forma contraditória: embora esperada a atividade dos estudantes, a concepção de ensino ainda centra-se no professor e, por isso, é justificável não desenvolver a aula em virtude da sua falta de preparação:

Eu não tenho vergonha de dizer que muitas vezes eu cancelei aula porque eu não sabia. Eu preparava uma aula, mas não sabia o que ia falar, não tinha estudado. Muitos professores podem fazer um trabalhinho, mas eu pensava, não vou lá fazer ridículo. Sempre que eu cancelava aula isso me incomodava. Eu sou professora, eu ganho pra isso e ter que cancelar porque eu não estava pronta, não estava capacitada para falar daquele assunto. (D. 8)

Relacionando estes fatos à trajetória docente iniciante, Tardif (2002) expressa que é na prática e na experiência que os professores vão descobrindo e reajustando os conflitos, as expectativas e as percepções, até então tidas sobre a profissão, sobre os estudantes e os processos de ensino e de aprendizagem. Assim, vão ampliando os horizontes e ampliando sua percepção para novos jeitos de ensinar, bem como nos diz uma entrevistada: "Eu penso: essa aula é muito teórica! Vou fazer alguma coisa diferente.” (D. 8)

Outra tensão encontrada nas narrativas dos docentes é com relação à visão que os docentes antigos ou mais experientes possuem dos docentes iniciantes:

A visão dos professores mais antigos, que têm cargos de direção, é que nós, professores novos, temos que pegar tudo, não economizam e botam pra trabalhar. Ao mesmo tempo, nós [professores iniciantes], temos uma visão um pouco contrária que se entramos recentemente, temos que ter um suporte. (D. 7)

Desde quando eu estava no doutorado, já sabia que eles [professores antigos] pensavam "deixa para os novos, eles têm que aprender a fazer as coisas e só aprendem fazendo". Alguns professores mais antigos, tem certa distância, embora nos dêem muitas coisas para fazer, eles dizem como devemos fazer. (D. 8)

Os professores iniciantes apreciam o respaldo dos colegas mais experientes, porém, desejam o reconhecimento. A essa experiência, harmonizam o espírito criativo e curioso que possuem, para desempenhar a prática docente e as atividades de gestão e pesquisa de modo 
inovador. Mesmo que, com todas as atribuições que lhes são destinadas, a experiência oportuniza o aprendizado ininterrupto nesse universo conhecido/desconhecido para os iniciantes.

Dessa forma, entendemos que os docentes em princípio de carreira, percebem as atividades de gestão no trabalho como ameaçadoras às suas necessidades de realização pessoal e profissional ou à sua saúde, perturbando as interações com outras atividades, à medida que esse ambiente apresenta demandas excessivas ou não contém ferramentas adequadas para enfrentar circunstâncias (LIMONGI-FRANÇA e RODRIGUES, 2014).

Os docentes afirmam, também, que a carga horária das múltiplas atividades que desempenham no ensino, na pesquisa e na gestão ${ }^{\text {iii }}$, reflete uma sobrecarga de trabalho: “Estamos sobrecarregados, pelo pouco número de professores permanentes em atuação. [...] O que em incomoda é a falta de justiça na distribuição das tarefas, eu me sinto sobrecarregada com essa situação." (D. 4). "No começo eu estava com muita aula, peguei as aulas de um colega que saiu para o doutorado." (D. 6). "Trabalho 40h semanais, não é dedicação exclusiva, mas na verdade, extrapolo essa carga horária, [...] Não tem uma semana que eu diga "hoje trabalhei só 40 horas semanais." (D. 7)

Embora atuem na gestão e administração universitária, os docentes iniciantes não receberam formação acadêmica ou profissional para tais atribuições. Desse modo, é na prática, na vivencia cotidiana e no relacionamento com colegas mais experientes, que os professores são incluídos na gestão, o que constitui uma trajetória ajustada e reformulada frente às realidades educativas atuais. Conforme Cunha et al. (2015, p. 81), "ao contrário de outras profissões, ao docente principiante, muitas vezes, cabe o exercício profissional em contextos complexos e exigentes na sua dimensão político-social e pedagógica”.

Este misto de responsabilidades, satisfações e incertezas justificam porque o início da profissão ocasiona diversas situações de stress, desconforto, irritabilidade e mal-estar. Podemos justificar que, tais efeitos ecoam da competitividade, produtividade acadêmica e as exigências do sistema educativo e mercantil têm sido concentradas muito mais na quantidade, do que na qualidade do que é produzido na universidade. Esta ocorrência, visivelmente promove a intensificação do trabalho, a pressão acadêmica e o esgotamento docente. Conforme destacam Spink e Alves (2011, p. 337),

Há poucos anos, quando professores universitários se encontravam para almoçar, a conversa, provavelmente, incluiria os diversos assuntos do dia - tais como congressos, bolsas, associações científicas -, além das inevitáveis fofocas que são partes do cotidiano humano. Provavelmente, também, terminariam a conversa de 
bom humor! Hoje é bem possível que um outro tema domine a mesa, mas, desta vez, deixando seus componentes de mau humor: as exigências crescentes da produção acadêmica e os ratings da avaliação CAPES.

Esta situação também foi evidenciada pelos docentes participantes da pesquisa: "as políticas de publicação e os custos para indexar são muito altos para a nossa área numa revista Qualis A1. É difícil e caro publicar [...]" (D. 7). "Uma coisa que me incomoda muito é essa exigência de publicações em Qualis A, fazer muita pesquisa é complicado para quem está começando [...]" (D. 6). Podemos perceber que os componentes sociais, educativos e econômicos da pesquisa científica, modificaram, ao longo dos anos, a realidade acadêmica nas universidades. As narrativas evidenciam que o momento da pesquisa e a cobrança pela socialização dos resultados são tensos. Frente às reconfigurações do cenário universitário, possivelmente, uma das relações que mais desencadeia situações de mal-estar seja a relação entre o ensino e a pesquisa. Acreditamos que as atividades de ensino e pesquisa são complementares. Porém, demandam competências, ações e procedimentos distintos. Nesta perspectiva, Kourganoff (1990, p. 46) assegura que "o ensino é a ação de alguém que ensina sobre alguém que recebe um ensinamento" e a pesquisa almeja "produzir novos conhecimentos, novas técnicas, novos problemas".

Kourganoff (1990) teceu uma análise sobre a organização do modelo universitário francês, onde criticou a ambiguidade das atribuições do docente-pesquisador e do pesquisador-docente, demonstrando que a associação entre ensino e pesquisa é arcaica e ineficiente, pois as atividades de pesquisa acabam por ter mais notoriedade e valorização do que as ações de ensino, ainda que o ofício principal do docente é o de ensinar. Os docentes entrevistados também afirmam que se sentem pressionados e internalizados pela pressão da pesquisa e produção científica e demonstram que é praticamente inevitável não ser pesquisador: "[...] sei que isso é exigido da gente, fui subjetivada por isso, eu sei que tenho que publicar" (D.1). "Eu me sinto pressionado [...] já tive artigos que poderia ter trabalhado mais, mas se eu não fizesse logo, outro ia fazer antes" (D. 5). Outros docentes percebem a situação como um processo automático: "Não é uma exigência da universidade, é do sistema de pesquisa como um todo, da área cientifica com o currículo" (D. 6) “[...] é automático estar pesquisando e publicando" (D. 7)

Conforme as narrativas, a produtividade científica está enraizada na profissionalidade docente e é decorrente das reconfigurações do sistema educacional e científico. Mas, a pesquisa também é percebida como "uma forma de socializar o nosso trabalho." (D. 1) "Eu não consigo imaginar fazendo outra coisa que não seja ciência.” (D. 2) 
Segundo Borsoi e Pereira (2013, p. 1220)

A produção científica é algo necessário e, ao mesmo tempo, desejado pelos
professores, em particular por aqueles que estão em programas de pós-graduação. O
problema é que essa necessidade e esse desejo esbarram na impossibilidade de
serem satisfeitos a contento, uma vez que há uma imensa demanda de atividades
acadêmicas, principalmente de ensino - de maneira especial, a sala de aula e as
orientações e as supervisões de alunos.

De acordo com algumas narrativas dos docentes, observa-se como a cobrança pela produtividade científica incomoda e potencializa o stress. Isso independe do "gostar ou não gostar" de pesquisar e produzir, visto que no exercício da docência universitária, é vital lidar com as demandas das múltiplas atividades e com a organização do tempo. Os docentes afirmam que a pesquisa faz parte do trabalho na universidade, sendo inevitável para a atualização profissional.

Para os docentes iniciantes, múltiplos são os aspectos em que a adaptação é uma necessidade, bem como afirma (D. 4): "Você vai descobrindo no processo como fazer, sem nenhum tipo de instrução..." Encontrar soluções alternativas para a falta de estrutura física é fundamental, segundo o docente (D. 5): "Mais um problema é não ter sala pra conversar com os orientandos [...] Uma das saídas que eu tenho procurado, foi dar a prova para eles fazerem em casa, trabalharem juntos, pesquisarem."

Essas disciplinas que eu dou, eu nunca vi no meu curso, isso é muito complicado,
porque no concurso pedia a formação que eu tinha, mas não era específica para
atuar. Mas vou muito atrás, pesquiso, estudo, embora, eu não tenha conhecimento
prático nenhum daquilo, e é o que os alunos perguntam [...] E isso acontece com a
maioria dos colegas. (D. 8)

As situações expressas nas narrativas encaminham, pelo menos, duas reflexões: Uma é com relação à necessidade do conhecimento específico na área de atuação. Conforme Antunes (2011, p. 30) afirma "quando o professor não domina a área do conhecimento em que atua, não consegue construir respostas metodológicas para os desafios educacionais que enfrenta em seu cotidiano [...]". Outro desafio é que por terem pouco conhecimento na área em que atuam, os docentes iniciantes universitários têm se deparado com dificuldades em abordar os saberes da formação profissional. Porém, podemos observar que, os docentes iniciantes são preocupados em aprimorar a prática educativa, ainda que, a formação inicial obtida não tem dado conta das atribuições diárias do trabalho.

Os oito docentes entrevistados atuam no ensino na graduação e quatro, também, na pós-graduação, expressando, por vezes, uma tensão na distribuição da carga horária, 
demandando uma reorganização do tempo para o desenvolvimento de tais atividades De acordo com alguns extratos: "Atualmente, dou quatro disciplinas por semestre na graduação, no restante dos períodos eu uso para preparar as aulas e avaliações dessas disciplinas. Sei que a minha carga horária de aula é altíssima, mas não vejo problema nenhum” (D. 5). "Atuo no ensino e na pesquisa na graduação e na pós-graduação, com uma disciplina em cada nível. No começo eu estava com muita aula, peguei as aulas de um colega que saiu para o doutorado" (D. 6).

Frente aos diferentes posicionamentos dos docentes, é necessário assumir que a docência é uma atividade complexa, que exige tanto uma preparação cuidadosa, como singulares condições de exercício, exigindo uma multiplicidade de saberes. De acordo com Tardif (2002, p. 33) o saber docente "se compõe, na verdade, de vários saberes provenientes de diferentes fontes". Os saberes da formação profissional, entendidos como o conjunto de saberes transmitidos pelas instituições de formação de professores; os saberes pedagógicos, que vinculam-se às concepções que conduzem o "saber-fazer" e a atividade educativa; os saberes disciplinares que correspondem aos campos do conhecimento, organizados por disciplinas; os saberes curriculares compreendidos como conteúdos, objetivos e métodos que servem de modelo para a atividade docente; por fim e não menos importantes, os saberes experienciais que, como o nome sugere, são os saberes advindos da experiência individual e coletiva do professor incorporados às habilidades de saber-fazer e de saber-ser docente (TARDIF, 2002).

Em muitos momentos, os saberes disciplinares e experienciais mobilizados, mais vinculados às atividades de pesquisa, em tensão com as demandas das atividades de ensino, invadem o que seria o espaço privado ou pessoal da vida do professor. É comum o desenvolvimento de projetos de pesquisa e de orientação em horários alternativos, que extrapolam o horário formal de trabalho, em decorrência da ampla demanda de atividades: "A pesquisa eu faço nos horários alternativos, porque não tenho laboratório, divido sala de permanência também, aí isso é um problema, então a pesquisa é feita a noite ou nos finais de semana" (D. 5) "Acaba que o trabalho supre todos os horários e ainda tem que achar um horário extra para ler TCC, dissertação ou participar de banca” (D. 7)

Estas narrativas demonstram que a falta de um espaço adequado, de tempo e de recursos na instituição, ocasionam uma extensão do espaço e do tempo profissional para os espaços e tempos privados e particulares. De acordo com Moyses (1994) na ausência de 
tempo e recursos, o professor acaba utilizando outras possibilidades que facilitam o dia-a-dia, ainda que isso lhe cause um certo desprazer.

Todos os docentes que entrevistamos desenvolvem alguma atividade relacionada à gestão, o que confirma que essas atividades vêm sendo funções acrescidas ao exercício docente (ZABALZA, 2004). Alguns dos entrevistados deste estudo são coordenadores de curso, membros do Conselho Universitário, avaliadores em comissões de bolsas para estudantes, quando não desempenham todas essas tarefas ao mesmo tempo: "Trabalho em atividades de gestão, onde participo em algumas comissões de bolsas e financiamentos e reuniões do colegiado do instituto" (D. 1) "Sou responsável por este espaço. Eu que faço a gestão e coordeno o pessoal que trabalha aqui" (D. 2) "Em termos de gestão, sou conselheiro do instituto no conselho universitário" (D. 5) "Participo das comissões de bolsas da pósgraduação, do núcleo docente estruturante, das reuniões da pós-graduação que são bem tensas pela questão da produtividade e das bolsas dos estudantes. [...] Sou coordenadora do curso de graduação" (D. 7)

Entrei na coordenação por falta de opção. Sou adjunta, mas acabo sendo a coordenadora oficial, por isso ninguém queria pegar o cargo, porque sabiam que seria assim. Esse cargo exige mais reuniões fora daqui, coordenar toda a parte do ensino, procurar o professor que não está dando aula, atendimento a alunos e familiares [...] É bem puxado ser coordenadora, tem muita coisa pra fazer (D. 8)

Por meio das narrativas, percebemos que os docentes iniciantes compõem um grupo atuante na gestão e administração universitária. Desempenhar funções gestoras e administrativas na universidade, segundo Graef (2010, p. 3) "são acréscimos de responsabilidades de natureza gerencial ou de supervisão atribuídas ao servidor ocupante de cargo efetivo, tendo como referência a correlação de atribuições”. Por ser uma atividade cada vez mais desempenhada por professores, inclusive pelos iniciantes, concordamos com Pereira et al. (2015, p. 270) que "diante da importância que os professores assumem na gestão universitária atual, não se pode desconsiderar o processo de profissionalização, visto que esses necessitam adquirir competências complementares para atuar nesse novo papel". Ou seja, em sua grande maioria, a formação inicial dos docentes não contemplou conhecimentos e experiências de administração ou gestão institucional que, na maioria dos casos, são aprendidas na vivência cotidiana do exercício da atividade. Por isso, a falta de conhecimentos referentes e a própria cobrança, seja pessoal ou social, podem desencadear situações de frustração e stress que afetam o docente no desenvolvimento das outras atividades como o ensino e a pesquisa. 
Portanto Silveira (2013) afirma que ter equilíbrio emocional, adaptação ao outro, tolerância e sensibilidade representam muito, pois, são fortes componentes para se ter o pessoal e o profissional em equilíbrio. Logo, adotar uma postura que dê conta da demanda de atividades, com a falta de estrutura física, com a preparação do ensino de conteúdos que, muitas vezes, nem o próprio professor não estudou determinados temas na sua formação inicial, necessitando ensiná-lo a estudantes de diferentes perfis e culturas, é trilhar o caminho da docência pela incerteza, mas também pelo profissionalismo. Ser professor universitário reporta que a profissão de "quem ensina tem que ter atualização, reflexão e adaptabilidade. Isso também se reflete em suas questões pessoais [...]" SILVEIRA (2013, p. 159)

Embora, os participantes afirmem que estão se adaptando à instituição e ao novo contexto da Educação Superior, as particularidades que envolvem a vida pessoal e profissional dos professores ratificam que vivemos uma época de turbulências que influenciam a formação, o exercício e comportamento profissional, sendo que, "a pessoa/profissional disposta à adaptação tem maior disposição em transformar as suas competências para aprofundá-las e ampliá-las continuamente [...]” MACIEL (2011, p. 2015)

\section{CONSIDERAÇÕES FINAIS}

Os docentes iniciantes têm vivenciado múltiplas tensões profissionais em decorrência das diferentes identidades e subjetividades que compõem os modos de ser professor e da constituição variada das equipes de trabalho na universidade, dos relacionamentos interpessoais e institucionais que estão sendo produzidos. Vivenciam, cada vez mais, exigências, tarefas e responsabilidades variadas e carecem de valorização, reconhecimento e tempo.

O professor, antes de ser professor, é um ser humano biopsicossocial. Como qualquer profissional, necessita de incentivos positivos externos, de assistência e de tempo adequado para o desempenho de suas atividades. Nas atividades de ensino, percebemos que é no percurso diário que aprendem a lidar com as turmas heterogêneas, com a falta de estrutura e recursos, com as inseguranças na organização e condução das aulas ou com as pressões de colegas mais experientes. E, por mais que durante a vida acadêmica na pós-graduação tenham desenvolvido muitas pesquisas científicas, sentem-se incomodados com as exigências, custos e concorrências para a publicação de artigos. Como pudemos constatar nas narrativas dos entrevistados, os problemas da profissão são múltiplos e, ora são superados, ora são silenciados. 
Os docentes entrevistados criam processos de adaptação necessários ao exercício da docência, visando contornar as adversidades vividas, como o cansaço e o stress, desempenhando as funções que lhes foram dadas, seguindo os modelos da experiência. De modo geral, o lado positivo da profissão é o sentimento de orgulho profissional. Os docentes consideram uma conquista "ser professor universitário". Acreditam que a profissão proporciona muita liberdade e flexibilidade no estilo de vida pessoal e profissional. E nessa inspiração e entusiasmo, que podemos observar a existência do eustress na vida docente universitária.

Neste cenário, os docentes iniciantes atuantes na universidade, desenvolvem a motivação não apenas nos momentos profissionais, mas também aspectos pessoais da vida humana, visto que estes são fundamentais para perceber as capacidades que possuem na promoção da autorrealização e da resiliência. Necessária à vida do professor, a resiliência é entendida como a capacidade de desenvolver estratégias para superar as adversidades cotidianas, envolvendo o cuidado de si e o autoconhecimento. Auxilia-nos, ainda, a lidar com as incertezas e desenvolver os processos de adaptação essenciais à vida individual e coletiva.

Portanto, entendemos que ser docente universitário é uma profissão em que constantemente se vivencia(rá) situações de incertezas e alegrias e é na reflexão sobre a sua prática e no desejo de transformação da educação que os momentos estressantes, de sobrecarga, de insegurança e esgotamento são superados e a profissão docente vai (re)assumindo outras forças, outras nuances.

\section{NOTAS EXPLICATIVAS}

'Os docentes entrevistados atuam nas seguintes unidades: Escola de Enfermagem - EEnf, Escola de Química e Alimentos - EQA, Instituto de Ciências Humanas e da Informação ICHI, Instituto de Oceanografia - IO, Instituto de Educação - IE, Instituto de Ciências Econômicas, Administrativas e Contábeis - ICEAC, Instituto de Ciências Biológicas - ICB.

${ }^{\text {ii }}$ Fase iniciante da docência, segundo Huberman (2000).

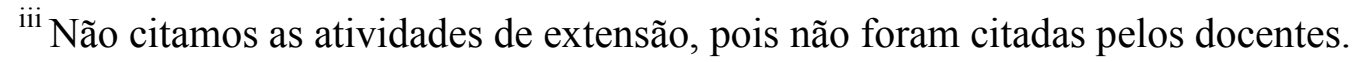

\section{REFERÊNCIAS}

ANTUNES, H. S. Ser aluna e ser professora: um olhar para os ciclos de vida pessoal e profissional. 1ed. Santa Maria: Editora da UFSM, 2011. 
BORSOI, I. C. F.; PEREIRA, F. S. Professores do ensino público superior: produtividade, produtivismo e adoecimento. Universitas Psychologica, v. 12, p. 1211-1233, 2013.

CATANI, A. M. O papel da universidade pública hoje: concepção e função. Jornal de Políticas Educacionais, v. 4, p. 4-14, 2008.

CUNHA, M. I. O lugar da formação do professor universitário: o espaço da pósgraduação em educação em questão. Revista Diálogo Educacional (PUCPR), v. 9, p. 81-90, 2009.

ZANCHET, B. M. B. A. A problemática dos professores iniciantes: tendência e prática investigativa no espaço universitário. Educação. Porto Alegre, v.33, n.3, p. 189-197, 2010.

O tema da formação de professores: trajetórias e tendências do campo na pesquisa e na ação. Educ. Pesquisa, n. 3, p. 609-625, 2013.

Aprendizagem da docência em espaços institucionais: é possível fazer avançar o campo da formação de professores? Avaliação (Campinas) [online]. 2014, vol.19, n.3, p. 789802.

BRACCINI, M. L.; FELDKERCHER, N. Inserção profissional, políticas e práticas sobre a inserção à docência: avaliando a produção dos Congressos Internacionais sobre o Professorado Iniciante. Avaliação (UNICAMP), v. 20, p. 73-85, 2015.

GIBBS, G. Análise de dados qualitativos. Porto Alegre: Artmed, 2009.

GRAEF, A. Cargos em Comissão e Funções de Confiança: Diferenças conceituais e práticas. Processo de Revisão do Estatuto e do Regimento Geral. Universidade Federal de Uberlândia. 2010. Disponível em: http://www.estatuto.ufu.br/sites/estatuto.ufu.br/files/cargofuncao-vs-funcoes-confianca.pdf Acesso em ago. 2015.

HUBERMAN, M. O ciclo de vida profissional dos professores. In: NÓVOA, A. (org.). Vidas de Professores. Porto: Porto Editora, 2000, p. 31-62.

ISAIA, S. M. A. O professor universitário no contexto de suas trajetórias. In: M. M. MOROSINI (Org.). Professor do ensino superior: identidade, docência e formação. $1^{\text {a } e d . ~}$ Brasília: Instituto Nacional de Estudos e Pesquisas Educacionais, 2000, v 1, p. 21-33.

. BOLZAN, D. P. V. Formação do professor do ensino superior: um processo que se aprende? Educação (UFSM), Santa Maria, v. 29, n.2, p. 121-133, 2004. 